\title{
The role of leukocytes in the formation and rupture of intracranial aneurysms
}

\author{
Michael J. Strong, Peter S. Amenta, Aaron S. Dumont, Ricky Medel \\ Department of Neurosurgery, Tulane University School of Medicine, New Orleans, LA 70112, USA.
}

\section{A B S T R A C T}

Ruptured intracranial aneurysms (IAs) affect a small proportion of the population; however, the morbidity and mortality is disproportionally high. Although little is known about IA formation, progression, and rupture, mounting evidence suggests that inflammation may play an important role in IA pathogenesis. There is emerging evidence to suggest that leukocytes play a key role in generating and maintaining a pathologic inflammatory response that leads to aneurysm formation and rupture. We present the current literature pertaining to the role of leukocytes in aneurysm formation, progression, and rupture. The contributions of individual cell types are detailed, with special attention paid to the cytokine and molecular profiles. The role of magnetic resonance imaging as a means by which to evaluate aneurysm-associated inflammation is reviewed. Finally, we discuss leukocytes as potential targets of pharmacologic intervention.

Key words: Aneurysm, inflammation, inflammatory cells, leukocytes, lymphocytes, macrophages, mast cells, neutrophils

\section{INTRODUCTION}

Stroke is the fourth leading cause of death in the United States and is a prominent cause of long-term disability. ${ }^{[1]}$ The prevalence of stroke among adults age 20 or older is estimated at 6.8 million, with 795,000 individuals experiencing a new or recurrent stroke annually. ${ }^{[1]}$ Subarachnoid hemorrhage (SAH), secondary to ruptured intracranial aneurysms (IAs) comprises $1-7 \%$ of all strokes. ${ }^{[2]}$ On an average $3.6-6 \%$ of the adult population harbor IAs; however, the rate of rupture is estimated to be between $0.05 \%$ and $0.5 \% .^{[3]}$ The small number of IAs that do rupture have a poor prognosis with a mortality rate of roughly $50 \%{ }^{[3]}$ Of those that survive the initial hemorrhage, approximately $30 \%$ remain severely disabled, resulting in a poor quality of life. ${ }^{[4]}$

The mechanisms of aneurysm genesis, maturation, and eventual rupture remain incompletely defined, yet new studies highlight multiple genetic and environmental factors that may contribute to the pathogenesis.

\begin{tabular}{|c|c|}
\hline \multicolumn{2}{|c|}{ Access this article online } \\
\hline Quick Response Code: & \\
\hline & $\begin{array}{l}\text { Website: } \\
\text { www.nnjournal.net }\end{array}$ \\
\hline & $\begin{array}{l}\text { DOI: } \\
\text { 10.4103/2347-8659.153972 }\end{array}$ \\
\hline
\end{tabular}

Chronic hypertension, binge drinking, and cigarette smoking have all been linked to aneurysm development and rupture..$^{[5-7]}$ Inflammation represents a potential common endpoint through which these diverse environmental stimuli enact pathologic changes in the intracranial vasculature, thus leading to aneurysm formation.

Animal aneurysm models, as well as analysis of human aneurysms, suggest that inflammation is a key mediator in the formation, progression, and rupture. ${ }^{[5,8-19]}$ Multiple studies have demonstrated the inflammatory response to be associated with persistent pathologic vascular remodeling in response to an insult to the vessel wall. Abnormal blood flow, chronically elevated blood pressure, and shear stress have all been linked to the induction of the inflammatory response as well as IA pathogenesis..$^{[6,12,20-29]}$ Central to the process of inflammation-driven vascular remodeling is endothelial and vascular smooth muscle cell (VSMC) dysfunction resulting in vessel weakening. ${ }^{[30]}$ The inflammatory response associated with vascular remodeling is composed of multiple complex cellular and biochemical processes. VSMCs, endothelial cells, and inflammatory cells participate in intercellular signaling, resulting in the recruitment of immune cells, such as leukocytes, to the vessel walls.

We review the current literature pertaining to the role of leukocytes in aneurysm formation, progression,

Corresponding Author: Dr. Michael J. Strong, Department of Neurosurgery, Tulane University School of Medicine,

New Orleans, LA 70112, USA. E-mail: mstrong@tulane.edu 
and rupture. The contributions of individual cell types are detailed, with special attention paid to the cytokine and molecular profiles. The role of magnetic resonance imaging (MRI) as a means by which to evaluate aneurysm-associated inflammation is reviewed. Finally, we discuss leukocytes as potential targets of pharmacologic intervention.

\section{DETECTION AND INVESTIGATION OF LEUKOCYTES IN HUMAN INTRACRANIAL ANEURYSM PATHOGENESIS}

Currently, the literature suggests that leukocyte infiltration of the intracranial vasculature may play various roles in the prolonged formation and acute rupture of IAs. Frösen et al. ${ }^{[12]}$ reported that IA walls obtained less than $12 \mathrm{~h}$ after rupture demonstrated T-cell and macrophage infiltration, as well as VSMC proliferation, indicating a chronic process that preceded rupture. In addition, the observation of leukocytes spread throughout aneurysm walls supports their role in the global deterioration of the vessel and suggests that their prominence in ruptured aneurysms is not an acute response to the sudden event. ${ }^{[31]}$

Transcriptome analysis of control vessels and IAs demonstrates upregulation of gene expression of the pro-inflammatory cytokines associated with leukocyte infiltration within aneurysm walls. ${ }^{[15,32-36]}$ Weinsheimer et $a l^{\left[{ }^{[35]}\right.}$ in an analysis of IAs obtained from autopsies within $24 \mathrm{~h}$ of death, showed upregulation of several pro-inflammatory genes, including, adherens junction, the mitogen-activated protein kinase pathway, and Notch signaling. Krischek et al. ${ }^{[36]}$ investigated gene expression on 10 IAs (6 ruptured and 4 unruptured) and determined that the most significantly upregulated pathway was antigen processing. Shi et al. ${ }^{[15]}$ interrogated 6 IAs using the illumina microarray platform and determined focal adhesion, extracellular matrix receptor interaction, cell communication, inflammatory response, and apoptosis to be the most significant functional pathways involved in IA pathogenesis. These findings indirectly implicate leukocyte infiltration as a major contributor to aneurysm genesis and progression.

Finally, immunohistochemical analysis of the animal model and human aneurysms has repeatedly demonstrated leukocytes within the aneurysmal walls. Chyatte et al. ${ }^{[20]}$ reported the presence of macrophages and T-lymphocytes within the walls of unruptured aneurysms. Ruptured aneurysms have also been found to harbor T-lymphocytes and macrophages within their walls. ${ }^{[12,31]}$ In a study of ruptured and unruptured IAs, Kataoka et al. ${ }^{[31]}$ observed leukocyte infiltration, particularly macrophages, in $50 \%$ of the unruptured and in all of the ruptured IAs. Using electron microscopy, the authors were able to demonstrate an association between advanced deterioration in the wall of ruptured aneurysms and the infiltration of leukocytes and macrophages. ${ }^{[31]}$ Frösen et al. ${ }^{[12]}$ also observed more prominent leukocyte infiltration in ruptured IAs when compared to unruptured IAs. These findings suggest that the structural architecture of ruptured aneurysms differs from that of unruptured aneurysms. Furthermore, leukocyte invasion appears to be a mediator of this change and a potential driving impetus behind the progression to aneurysm rupture.

\section{ROLE OF MACROPHAGES}

Animal and clinical studies have identified macrophages as important contributors to the formation and rupture of aneurysms. These cells participate in the synthesis and secretion of matrix metalloproteinases (MMPs) and elastases, which play significant roles in the degradation of the extracellular matrix and internal elastic lamina. Histopathological analysis of both unruptured and ruptured aneurysms has repeatedly identified macrophage infiltration within the aneurysm walls. $^{[12,20,37]}$ In addition, Ruzevick et al. ${ }^{[38]}$ observed the pro-inflammatory haptoglobin 2-2 genotype to be associated with larger aneurysms and increased macrophage infiltration within the aneurysm walls.

Macrophage-depleted mice have been shown to have a moderate protective advantage from aneurysm formation and rupture, suggesting macrophages play a critical role in the aneurysm pathogenesis. ${ }^{[13,39]}$ Corroborating this hypothesis are two animal studies investigating the role of monocyte chemoattractant protein 1 (MCP-1), an important macrophage chemoattractant that has been studied in atherosclerosis and abdominal aortic aneurysms (AAA). ${ }^{\left[{ }^{[0,41]}\right.}$ By using MCP-1 knockout (KO) mice, both Aoki et al. ${ }^{[9]}$ and Kanematsu et al. ${ }^{\left[{ }^{[13]}\right.}$ were able to demonstrate a decrease in aneurysm formation and macrophage accumulation. Aoki et al. ${ }^{[9]}$ also reported that inhibiting MCP-1 activity using a dominant negative mutant of MCP-1 resulted in the inhibition of aneurysm progression in rats. MCP-1 deficient mice also demonstrated decreased macrophage accumulation and expression of MMP-2 and MMP-9. ${ }^{[9]}$ A recent study conducted by Chalouhi et al. ${ }^{[42]}$ surveyed the cytokines and chemokines in aneurysm lumen blood and found an increase in chemoattractant cytokines interleukin-7 (IL-7), IL-8, and MCP-1, suggesting active recruitment of inflammatory cells into the aneurysm.

Nuclear factor- $\mathrm{\kappa B}(\mathrm{NF}-\kappa \mathrm{B})$ is a family of transcriptional factors involved in regulating the expression of a variety of inflammatory factors including MCP-1. Aoki et al. ${ }^{[43]}$ investigated the role of NF- $\mathrm{KB}$ in the 
initiation and progression of IAs using animal models. The authors were able to demonstrate that NF- $\kappa B$ participates in the initiation of IA formation through transactivation of many downstream genes related to macrophage recruitment and vascular inflammation, such as MCP-1, vascular cell adhesion molecule 1 (VCAM-1), MMP-2, MMP-9, IL-1 $\beta$, and inducible nitric oxide synthase (iNOS). ${ }^{[43]}$ In addition, NF-кB decoy oligodeoxynucleotides (ODNs), which inhibit $\mathrm{NF}-\kappa \mathrm{B}$, abrogated the upreguation of inflammatory factors, including MCP-1. In an additional study conducted by the same group, Aoki et al. ${ }^{[44]}$ linked MCP-1 expression in VSMCs with Ets-1, a transcription factor implicated in many vascular inflammatory diseases. Ets-1 binds to the promoter region of MCP-1 resulting in increased Ets-1 expression. Utilizing the knowledge obtained from previous studies on the role of NF- $\kappa \mathrm{B}$ and Ets-1, Aoki et al. ${ }^{[45]}$ showed that treating rats with chimeric decoy ODNs, designed to simultaneously inhibit NF- $\mathrm{\kappa B}$ and Ets-1, reduced aneurysm size while thickening aneurysm walls of preexisting aneurysms. Furthermore, decreased expression of MCP-1 and reduced macrophage infiltration was observed in rats treated with the decoy ODNs.

Additional molecular signaling molecules associated with macrophage-induced aneurysm formation include tumor necrosis factor alpha (TNF- $\alpha$ ) and stromal cell-derived factor-1 (SDF-1). Several studies have suggested that TNF- $\alpha$ is a key mediator in aneurysm development through the activation of several cytokines and MMPs. ${ }^{[17-19,46]}$ TNF- $\alpha$ has been shown to upregulate MCP-1, which in return attracts macrophages, thereby leading to additional TNF- $\alpha$ expression in a positive feedback loop. ${ }^{[18]}$ Using TNF- $\alpha$ KO mice, Starke et $a .^{\left[{ }^{[18]}\right.}$ demonstrated a reduction in IA formation and rupture. Additional studies using a synthesized TNF- $\alpha$ inhibitor 3, 6'dithiothalidomide (DTH) substantiated the results from the KO experiments. Starke et al. ${ }^{[18]}$ also showed DTH to inhibit IA progression with fewer ruptured IA in the treatment group compared to the control group. Furthermore, using tumor necrosis factor receptor superfamily member 1a (TNFR1) deficient mice, Aoki et al. ${ }^{[46]}$ demonstrated suppressed IA formation with decreased NF- $\kappa$ B activation, reduced MCP-1 and cyclooxygenase 2 (COX-2) expression, and fewer infiltrating macrophages. These results suggest that TNF- $\alpha /$ TNFR1 signaling is critical in IA pathogenesis.

Stromal cell-derived factor-1 is an important chemokine that promotes inflammation directly as well as through angiogenesis. ${ }^{[4]}$ Macrophage recruitment and retention around new blood vessels has been shown to be mediated by SDF-1. ${ }^{[48]}$ Expression of SDF-1 in IAs was recently evaluated in a study conducted by Hoh et al., ${ }^{[47]}$ wherein
SDF-1 was present in the walls of both human and mouse aneurysms. Hoh et al. ${ }^{[47]}$ also found SDF-1 promotes aneurysm wall angiogenesis through endothelial cell tube formation and macrophage infiltration. Inhibiting SDF-1, using anti-SDF-1 blocking antibodies, supressed murine aneurysm wall angiogenesis and resulted in the development of significantly fewer IAs compared to control mice.

Macrophages mediate flow-induced vascular remodeling, in part, through the release of MMPs, a process that under physiologic conditions, preserves vascular integrity and health. ${ }^{[39,49]}$ However, increased levels of MMP expression, particularly MMP-2 and MMP-9, have been reported in IAs. ${ }^{[10,11,50,51]}$ Studies using broad-based MMP inhibitors, such as doxycycline, have shown significant reductions in the incidence of IAs in animal models. ${ }^{[49,52]}$ Tolylsam, a selective inhibitor for MMP-2, -9, and -12 also abolished the progression of IA, although it did not reduce the incidence of total aneurysmal changes. ${ }^{[10]}$ Using more refined inhibition techniques, a greater understanding for the role of MMPs has materialized. Nuki et al. ${ }^{[52]}$ showed that MMP-9 KO mice, but not MMP-2 KO mice, diminished the incidence of IAs. A separate study by Ota et al. ${ }^{[49]}$ also demonstrates a reduced incidence of IAs in MMP-9 $\mathrm{KO}$ animals but not in MMP-12 KO animals.

Whereas MMP-9 is the main gelatinase, MMP-12 is the main elastase secreted from macrophages. Since MMP-12 appears to have no effect on aneurysm formation and rupture, other sources of elastases are likely. Neutrophil elastase is involved in atherosclerotic plaques and AAA and is produced by not only neutrophils but also macrophages and vascular endothelial cells. ${ }^{[53,54]}$ Furthermore, neutrophil depletion studies inhibited AAA development through a non-MMP-2 and non-MMP-9-mediated mechanism, implying other mediators must exist, including the possibility of neutrophil elastase. ${ }^{[55]}$

Another protease that is of interest is the cathepsin family (B, D, K, and S), which have been shown to be expressed in IAs and promote their progression. ${ }^{[56,57]}$ Specifically, histological analysis of ruptured aneurysms exhibited a cluster of macrophages expressing cathepsin $\mathrm{D}$ within the aneurysm wall where there was evidence of collagen erosion. ${ }^{[31]}$ Multiple studies suggest that a polarized macrophage population is associated with a variety of diseases including atherosclerosis, inflammatory lung disease, and inflammatory diseases of the nervous system. ${ }^{[58-62]}$ Two populations of macrophages, the M1 (pro-inflammatory) and M2 (anti-inflammatory) subtypes, have been identified. Predominance of the M1 subtype has been implicated in aneurysm progression and rupture. 
The M1 population is pro-inflammatory and secretes high levels of IL-2, IL-23, IL-6, IL-1, and TNF- $\alpha .{ }^{[63]}$ The M2 population is antiinflammatory and secretes high levels of IL-10. Hasan et al. ${ }^{[63]}$ examined 10 patients with IAs (5 unruptured and 5 ruptured) for the presence of M1 and M2 macrophage populations. The authors demonstrated a predominance of M1 over M2 macrophages within the walls of ruptured aneurysms and observed an increase in mast cells in ruptured aneurysms compared to unruptured aneurysms. The authors hypothesized that the imbalance between M1 and M2 may be in part due to the effects of mast cells. Given these results, the interplay between M1 and M2 phenotypes appears to be important in the aneurysm pathogenesis and warrants further investigation.

\section{ROLE OF MAST CELLS}

Mast cells are resident leukocytes that contain cytoplasmic granules rich in histamine and heparin, as well as, the pro-inflammatory cytokines, TNF- $\alpha$, IL-1, IL-3, IL-4, IL-5, IL-8 and IL-13, and transforming growth factor-beta. ${ }^{[64,65]}$ Mast cell degranulation and release of cytokines has been linked with vascular inflammatory processes, such as, atherosclerosis and AAAs. ${ }^{[66,67]}$ Recent investigations have targeted mast cells as contributors to IA genesis and progression. In a study conducted by Ishibashi et al., ${ }^{[65]}$ an increase in the total number of mast cells during IA formation was observed using a rat model. Mast cell degranulation inhibitors suppressed IA progression through attenuation of the local chronic inflammatory response, as was evident from decreased $\mathrm{NF}-\kappa \mathrm{B}$ activation, macrophage infiltration, and expression of MCP-1, MMPs, and IL-1 $\beta .{ }^{[65]}$ In addition, Ollikainen et al. ${ }^{[68]}$ demonstrated that mast cells in the wall of IAs were associated with histopathological changes consistent with wall remodeling, lipid accumulation, and inflammatory cell infiltration. Finally, Hasan et al. ${ }^{[63]}$ observed increased mast cells in ruptured IAs relative to unruptured IAs. Taken together, these studies indicate that mast cell degranulation play a critical role in aneurysm formation and may contribute to IA rupture.

\section{ROLE OF NEUTROPHILS}

Neutrophils are recruited to sites of injury and are a hallmark of acute inflammation. Although the contribution of neutrophils in IA formation is largely undefined, evidence from investigations into AAA pathogenesis offers insight into their role. Animal models have demonstrated progressively increasing neutrophil infiltration into the walls of AAAs over the course of aneurysm development. ${ }^{[55,69]}$

Neutrophil recruitment to the vascular wall may be associated with macrophage infiltration. Mice treated with an antineutrophil-antibody showed a decreased number of macrophages compared to wild-type (WT) mice. ${ }^{[55]}$ Furthermore, depletion of neutrophils attenuated the size and incidence of AAA. Diminished macrophage infiltration in aneurysms of neutrophil-depleted mice is not associated with a decrease in chemoattracts such as MCP-1 and MIP- $1 \alpha{ }^{[55]}$ This suggests that additional mediators are contributing to this complex interaction. Importantly, there was no difference in expression of MMP-2 and MMP-9, despite a decrease in macrophage infiltration.

The presence of neutrophils was recently reported by Marbacher et al. ${ }^{[70]}$ using a decellularized rat aneurysm model. This rat model simulated the loss of mural cells (endothelial and VSMCs), a hallmark of ruptured cerebral aneurysms. ${ }^{[12,31]}$ The ruptured aneurysms displayed marked adventitial fibrosis and inflammation, complete wall disruption, and increased neutrophil accumulation in unorganized intraluminal thrombus. ${ }^{[70]}$ Neutrophils trapped in unorganized thrombus are a major source of matrix-degrading proteases. Intraluminal thrombus is a site of protease and cytotoxic compound release leading to wall inflammation and subsequent matrix degradation..$^{[55,71]}$

Myeloperoxidase (MPO) is a peroxidase enzyme that catalyzes the formation of a number of reactive oxidant species and is primarily produced by neutrophils. ${ }^{[72]}$ Along with a well-known role in host mechanisms against pathogens, MPO has recently been implicated in the initiation and destabilization of atherosclerotic plaques. ${ }^{[73]}$ In a study conducted by Gounis et al., ${ }^{[74]}$ MPO was detected in all three ruptured IAs and 10 out of 20 unruptured IAs. ${ }^{[74]}$ Additionally, Gounis et al. ${ }^{[74]}$ demonstrated that MPO positivity was a significant predictor of 5-year aneurysm rupture rate. An emerging picture suggests a key factor in aneurysm formation and rupture is the ongoing inflammatory process mediated by infiltration of leukocytes. This suggests that MPO may play an important role in the aneurysm pathogenesis. Therefore, MPO may also serve as a potential biomarker.

Neutrophils represent a potential therapeutic target for pharmacologic interventions designed at preventing aneurysm progression and rupture. Hannawa et al. ${ }^{[69]}$ demonstrated suppressed AAA formation in L-selectin KO mice. L-selectin, an adhesion molecule expressed on the surface of most leukocytes, is responsible for the recruitment of immune cells. ${ }^{[75-77]}$ Hannawa et al. ${ }^{[69]}$ postulated that the diminished AAA formation seen in WT mice compared with the L-selectin $\mathrm{KO}$ mice is most likely due to the impaired recruitment of neutrophils 
and macrophages. Specifically, since neutrophils are present in the aortic wall before macrophages in WT mice, a decrease in neutrophils in the L-selectin $\mathrm{KO}$ mice is most likely due to the lack of L-selectin. ${ }^{[69]}$

\section{ROLE OF LYMPHOCYTES}

The contribution of $\mathrm{T}$ and $\mathrm{B}$ lymphocytes to IA formation is an additional avenue of exploration. B lymphocytes are rarely detected, and their role in IA pathogenesis is unclear. ${ }^{[20]}$ However, T-lymphocytes have been documented within aneurysm walls ${ }^{[12,20]}$ and CD8+ T-cells have been linked with AAA development. ${ }^{[78]}$ T-lymphocytes have been shown to secrete pro-inflammatory cytokines including TNF- $\alpha$, IFN- $\gamma$, and IL-6. ${ }^{[79]}$ T-lymphocytes were detected within the walls of ruptured aneurysms and were associated with increased infiltration in samples taken $<12 \mathrm{~h}$ from rupture. These results indicate that this observation was not reactive. ${ }^{[12]}$ Based on these observations, T-lymphocytes may play an important role in not only aneurysm formation, but also rupture. Additional studies focused on the role of lymphocytes in IA formation and rupture are necessary to further our understanding of the aneurysm pathogenesis.

\section{DETERMINING INFLAMIMATORY STATUS USING IMAGING}

The apparent relationship between inflammation and aneurysm rupture is of clinical significance and may provide an avenue through which more accurate predictions of aneurysm rupture can be made. MRI is currently being explored as a noninvasive modality with the potential to evaluate the inflammatory state of aneurysms.

Hasan et al ${ }^{[80]}$ have reported on ferumoxytol-enhanced MRI images to evaluate aneurysm walls for macrophage infiltration. Ferumoxytol, which is used to treat iron deficiency anemia in patients with chronic renal failure, is a Food and Drug Administration approved drug consisting of an iron oxide nanoparticle. ${ }^{[81,82]}$ The investigators imaged 19 unruptured aneurysms in 11 patients and determined that images acquired $72 \mathrm{~h}$ postinfusion of ferumoxytol were optimal for detecting macrophages within the aneurysm wall.

In a follow-up study, Hasan et al. ${ }^{[83]}$ found that early uptake (within $24 \mathrm{~h}$ of infusion) of ferumoxytol in unruptured aneurysm walls suggested an active inflammatory process leading to aneurysm instability, ultimately resulting in rupture within 6 months. This hypothesis was validated with increased expression of COX-2 and mPGES-1 and an increased number of macrophages in aneurysms with early MRI signal changes. These results showed similar expression patterns to ruptured aneurysms. Unruptured aneurysms with late uptake (72 $\mathrm{h}$ postinfusion), did not rupture or increase in size after 6 months of follow-up. As a result, these studies show that ferumoxytol signal changes may indicate a greater risk of aneurysm rupture and suggest macrophage infiltration as a potential marker of aneurysms more likely to rupture.

Myeloperoxidase-specific paramagnetic magnetic resonance (MR) contrast agents, which are specific for MPO activity, have been evaluated in animal and tissue culture studies to examine their utility for imaging active inflammation..$^{[74,84,85]}$ Rabbit studies have shown promise for the use of an MPO-specific paramagnetic MR contrast agent, di-5-hydroxytryptamide of gadopentetate dimeglumine, in detecting local inflammation ${ }^{[86]}$ Since MPO has been detected in IAs, specially ruptured IAs, using MPO-specific contrast agents to monitor MPO within IAs will predict active inflammation and may aid in the management of unruptured aneurysms.

\section{FUTURE DIRECTION AND THERAPEUTIC APPROACHES}

Despite advances in microsurgical and endovascular therapy, outcomes following IA rupture remain poor. Thus, the identification of indicators of pending rupture and the development of pharmacologic interventions designed at limiting aneurysm progression and rupture are of great clinical interest. A better understanding of the relationship between inflammation and IA pathogenesis is a promising avenue of exploration, as there are multiple cellular and molecular targets for potential exploitation. Pharmacologic interventions targeting inflammation-driven IA formation and progression have shown promise in animal and human studies ${ }^{[5]}$ These drugs target inflammatory molecules such as TNF- $\alpha$ (DTH), ${ }^{[18]}$ NF- $\kappa B$ (decoy ODN), ${ }^{[43]}$ Ets-1 (decoy ODN), ${ }^{[45]}$ SDF-1 (blocking anti-SDF-1 antibodies), ${ }^{[47]}$ MMPs (tolylsam and doxycline), ${ }^{[10,49,52]}$ MCP1 (7ND) ${ }^{[9]}$ and cathepsins (NC-2300) ${ }^{[56]}$ [Table 1]. In addition, mast cell degranulation inhibitors (tranilast and emedastine difumarate) $)^{[65]}$ have also been tested. All these therapeutic agents have shown to decrease aneurysm size in experimental animal models. Ferumoxytol-enhanced and MPO-specific paramagnetic MRI appear to offer a possible means by which to evaluate the inflammatory profile of individual aneurysms. Additional investigations into the role of inflammation and IA formation, progression, and rupture are required to better elucidate potential clinically relevant pathways for intervention. 
Table I: Major leukocyte inflammatory mediators and targeted therapies for intracranial aneurysms

\begin{tabular}{|c|c|}
\hline $\begin{array}{l}\text { Major } \\
\text { molecules }\end{array}$ & $\begin{array}{l}\text { Targeted therapies for } \\
\text { intracranial aneurysms }\end{array}$ \\
\hline \multicolumn{2}{|l|}{$\begin{array}{l}\text { Common inflammatory } \\
\text { mediators }\end{array}$} \\
\hline TNF- $\alpha$ & $\mathrm{DTH}^{[18]}$ \\
\hline$N F-\kappa B$ & Decoy ODN ${ }^{[45]}$ \\
\hline Ets-1 & Decoy ODN ${ }^{[45]}$ \\
\hline \multicolumn{2}{|l|}{ VCAM-1 } \\
\hline \multicolumn{2}{|l|}{ iNOS } \\
\hline \multicolumn{2}{|l|}{ L-selectin } \\
\hline MCP-1 & $7 \mathrm{ND}^{[9]}$ \\
\hline SDF-1 & Blocking anti-SDF-1 antibody ${ }^{[4]]}$ \\
\hline \multicolumn{2}{|l|}{ Macrophages } \\
\hline \multicolumn{2}{|l|}{ IL-1 $\beta$, IL-2, IL-6, IL-23 } \\
\hline \multicolumn{2}{|l|}{ MIP- $1 \alpha$} \\
\hline Cathepsins & NC-23000 $[56]$ \\
\hline MMP-2, MMP-9 & $\begin{array}{l}\text { Tolylsam (selective) and } \\
\text { doxycline (broad) }{ }^{[10,49,52]}\end{array}$ \\
\hline \multicolumn{2}{|l|}{ Neutrophils } \\
\hline \multicolumn{2}{|l|}{ IL-1 $\beta$} \\
\hline \multicolumn{2}{|l|}{ Neutrophil elastase } \\
\hline \multicolumn{2}{|l|}{ Lymphocytes } \\
\hline \multicolumn{2}{|l|}{ IFN- $\gamma$} \\
\hline \multicolumn{2}{|l|}{ IL-6 } \\
\hline \multicolumn{2}{|l|}{ Mast cells } \\
\hline IL-1, IL-3, IL-4, IL-5, & Degranulation inhibitors (tranilast \\
\hline IL-8, IL-13 & and emedastine difumarate) ${ }^{[65]}$ \\
\hline TGF- $\beta$ & \\
\hline
\end{tabular}

TNF- $\alpha$ : tumor necrosis factor-alpha; DTH: 3,6'dithiothalidomide; NF-kB: nuclear factor-KB; ODN: oligodeoxynucleotide; VCAM-1: vascular cell adhesion molecule; iNOS: inducible nitric oxide synthase; MCP-1: monocyte chemoattractant protein-1; 7ND: N-terminal deletion variant of MCP-1; SDF-1: stromal cell-derived factor 1; MMP: matrix metalloproteinase; MIP-1 $\alpha$ : macrophage inflammatory proteins-1-alpha; IFN- $\gamma$ : interferon gamma; TGF- $\beta$ : transforming growth factor beta; IL: interleukin

\section{REFERENCES}

1. Go AS, Mozaffarian D, Roger VL, Benjamin EJ, Berry JD, Blaha MJ, Dai S, Ford ES, Fox CS, Franco S, Fullerton HJ, Gillespie C, Hailpern SM, Heit JA, Howard VJ, Huffman MD, Judd SE, Kissela BM, Kittner SJ, Lackland DT, Lichtman JH, Lisabeth LD, Mackey RH, Magid DJ, Marcus GM, Marelli A, Matchar DB, McGuire DK, Mohler ER, Moy CS, Mussolino ME, Neumar RW, Nichol G, Pandey DK, Paynter NP, Reeves MJ, Sorlie PD, Stein J, Towfighi A, Turan TN, Virani SS, Wong ND, Woo D, Turner MB. Executive summary: heart disease and stroke statistics - 2014 update: a report from the American Heart Association. Circulation 2014;129:399-410.

2. Feigin VL, Lawes CM, Bennett DA, Anderson CS. Stroke epidemiology: a review of population-based studies of incidence, prevalence, and case-fatality in the late 20th century. Lancet Neurol 2003;2:43-53

3. Wardlaw JM, White PM. The detection and management of unruptured intracranial aneurysms. Brain 2000;123:205-21.

4. Hop JW, Rinkel GJ, Algra A, van Gijn J. Case-fatality rates and functional outcome after subarachnoid hemorrhage: a systematic review. Stroke 1997;28:660-4.

5. Chalouhi N, Ali MS, Jabbour PM, Tjoumakaris SI, Gonzalez LF, Rosenwasser RH, Rosenwasser R, Koch W, Dumont A. Biology of intracranial aneurysms: role of inflammation. $J$ Cereb Blood Flow Metab 2012;32:1659-76.

6. Chalouhi N, Ali MS, Starke RM, Jabbour PM, Tjoumakaris SI, Gonzalez LF, Rosenwasser RH, Koch WJ, Dumont AS. Cigarette smoke and inflammation: role in cerebral aneurysm formation and rupture. Mediators Inflamm 2012;2012:271582.

7. Juvela S, Hillbom M, Numminen H, Koskinen P. Cigarette smoking and alcohol consumption as risk factors for aneurysmal subarachnoid hemorrhage. Stroke 1993;24:639-46.

8. Krex D, Schackert HK, Schackert G. Genesis of cerebral aneurysms - an update. Acta Neurochir (Wien) 2001;143:429-48.

9. Aoki T, Kataoka H, Ishibashi R, Nozaki K, Egashira K, Hashimoto N. Impact of monocyte chemoattractant protein-1 deficiency on cerebral aneurysm formation. Stroke 2009;40:942-51.

10. Aoki T, Kataoka H, Morimoto M, Nozaki K, Hashimoto N. Macrophage-derived matrix metalloproteinase-2 and -9 promote the progression of cerebral aneurysms in rats. Stroke 2007;38:162-9.

11. Bruno G, Todor R, Lewis I, Chyatte D. Vascular extracellular matrix remodeling in cerebral aneurysms. J Neurosurg 1998;89:431-40.

12. Frösen J, Piippo A, Paetau A, Kangasniemi M, Niemelä M, Hernesniemi J, Jaaskelainen J. Remodeling of saccular cerebral artery aneurysm wall is associated with rupture: histological analysis of 24 unruptured and 42 ruptured cases. Stroke 2004;35:2287-93.

13. Kanematsu Y, Kanematsu M, Kurihara C, Tada Y, Tsou TL, van Rooijen N, Lawton MT, Young WL, Liang EI, Nuki Y, Hashimoto T. Critical roles of macrophages in the formation of intracranial aneurysm. Stroke 2011;42:173-8.

14. Kilic T, Sohrabifar M, Kurtkaya O, Yildirim O, Elmaci I, Günel M, Pamir M. Expression of structural proteins and angiogenic factors in normal arterial and unruptured and ruptured aneurysm walls. Neurosurgery 2005;57:997-1007.

15. Shi C, Awad IA, Jafari N, Lin S, Du P, Hage ZA, Shenkar R, Getch C, Bredel M, Batjer H, Bendok B. Genomics of human intracranial aneurysm wall. Stroke 2009;40:1252-61.

16. Aoki T, Nishimura M, Matsuoka T, Yamamoto K, Furuyashiki T, Kataoka H, Kitaoka S, Ishibashi R, Ishibazawa A, Miyamoto S, Morishita R, Ando J, Hashimoto N, Nozaki K, Narumiya S. PGE(2) - EP(2) signalling in endothelium is activated by haemodynamic stress and induces cerebral aneurysm through an amplifying loop via NF-kappaB. Br J Pharmacol 2011;163:1237-49.

17. Ali MS, Starke RM, Jabbour PM, Tjoumakaris SI, Gonzalez LF, Rosenwasser RH, Owens GK, Koch WJ, Greig NH, Dumont AS. TNF- $\alpha$ induces phenotypic modulation in cerebral vascular smooth muscle cells: implications for cerebral aneurysm pathology. J Cereb Blood Flow Metab 2013;33:1564-73.

18. Starke RM, Chalouhi N, Jabbour PM, Tjoumakaris SI, Gonzalez LF, Rosenwasser RH, Wada K, Shimada K, Hasan D, Greig N, Owens G, Dumont A. Critical role of TNF- $\alpha$ in cerebral aneurysm formation and progression to rupture. J Neuroinflammation 2014;11:77.

19. Jayaraman T, Berenstein V, Li X, Mayer J, Silane M, Shin YS, Niimi Y, Klç T, Gunel M, Berenstein A. Tumor necrosis factor alpha is a key modulator of inflammation in cerebral aneurysms. Neurosurgery 2005;57:558-64.

20. Chyatte D, Bruno G, Desai S, Todor DR. Inflammation and intracranial aneurysms. Neurosurgery 1999;45:1137-46.

21. Hashimoto T, Meng H, Young WL. Intracranial aneurysms: links among inflammation, hemodynamics and vascular remodeling. Neurol Res 2006;28:372-80.

22. Turjman AS, Turjman F, Edelman ER. Role of fluid dynamics and inflammation in intracranial aneurysm formation. Circulation 2014;129:373-82.

23. Penn DL, Komotar RJ, Sander Connolly E. Hemodynamic mechanisms underlying cerebral aneurysm pathogenesis. $J$ Clin Neurosci 2011;18:1435-8.

24. Chien S. Effects of disturbed flow on endothelial cells. Ann Biomed Eng 2008;36:554-62.

25. Nagel T, Resnick N, Dewey CF Jr, Gimbrone MA Jr. Vascular endothelial cells respond to spatial gradients in fluid shear stress by enhanced activation of transcription factors. Arterioscler Thromb Vasc Biol 1999;19:1825-34.

26. Tardy Y, Resnick N, Nagel T, Gimbrone MA Jr, Dewey CF Jr. Shear stress gradients remodel endothelial monolayers in vitro via a cell proliferation-migration-loss cycle. Arterioscler Thromb Vasc Biol 1997; 17:3102-6.

27. Burridge K, Chrzanowska-Wodnicka M. Focal adhesions, contractility, and signaling. Annu Rev Cell Dev Biol 1996;12:463-518. 
28. Wang N, Tytell JD, Ingber DE. Mechanotransduction at a distance: mechanically coupling the extracellular matrix with the nucleus. Nat Rev Mol Cell Biol 2009;10:75-82.

29. Takeichi M. The cadherins: cell-cell adhesion molecules controlling animal morphogenesis. Development 1988;102:639-55.

30. Jamous MA, Nagahiro S, Kitazato KT, Tamura T, Aziz HA, Shono M, Satoh K. Endothelial injury and inflammatory response induced by hemodynamic changes preceding intracranial aneurysm formation: experimental study in rats. $J$ Neurosurg 2007;107:405-11.

31. Kataoka K, Taneda M, Asai T, Kinoshita A, Ito M, Kuroda R. Structural fragility and inflammatory response of ruptured cerebral aneurysms. A comparative study between ruptured and unruptured cerebral aneurysms. Stroke 1999;30:1396-401.

32. Kurki MI, Häkkinen S-K, Frösen J, Tulamo R, von und zu Fraunberg M, Wong G, Tromp G, Niemelä M, Hernesniemi J, Jääskeläinen JE, Ylä-Herttuala S. Upregulated signaling pathways in ruptured human saccular intracranial aneurysm wall: an emerging regulative role of toll-like receptor signaling and nuclear factor- $\mathrm{\kappa B}$, hypoxia-inducible factor-1A, and ETS transcription factors. Neurosurgery 2011;68:1667-76.

33. Nakaoka H, Tajima A, Yoneyama T, Hosomichi K, Kasuya H, Mizutani T, Inoue I. Gene expression profiling reveals distinct molecular signatures associated with the rupture of intracranial aneurysm. Stroke 2014;45:2239-45

34. Pera J, Korostynski M, Krzyszkowski T, Czopek J, Slowik A, Dziedzic T, Piechota M, Stachura K, Moskala M, Przewlocki R, Szczudlik A. Gene expression profiles in human ruptured and unruptured intracranial aneurysms: what is the role of inflammation? Stroke 2010;41:224-31.

35. Weinsheimer S, Lenk GM, van der Voet M, Land S, Ronkainen A, Alafuzoff I, Kuivaniemi H, Tromp G. Integration of expression profiles and genetic mapping data to identify candidate genes in intracranial aneurysm. Physiol Genomics 2007;32:45-57.

36. Krischek B, Kasuya H, Tajima A, Akagawa H, Sasaki T, Yoneyama T, Ujiie H, Kubo O, Bonin M, Takakura K, Hori T, Inoue I. Network-based gene expression analysis of intracranial aneurysm tissue reveals role of antigen presenting cells. Neuroscience 2008;154:1398-407.

37. Nakajima N, Nagahiro S, Sano T, Satomi J, Satoh K. Phenotypic modulation of smooth muscle cells in human cerebral aneurysma walls. Acta Neuropathol 2000;100:475-80.

38. Ruzevick J, Jackson C, Pradilla G, Garzon-Muvdi T, Tamargo RJ. Aneurysm formation in proinflammatory, transgenic haptoglobin 2-2 mice. Neurosurgery 2013;72:70-6.

39. Nuki Y, Matsumoto MM, Tsang E, Young WL, van Rooijen N, Kurihara C, Hashimoto T. Roles of macrophages in flow-induced outward vascular remodeling. $J$ Cereb Blood Flow Metab 2009:29:495-503.

40. Moehle CW, Bhamidipati CM, Alexander MR, Mehta GS, Irvine JN, Salmon M, Upchurch GR, Jr, Kron IL, Owens GK, Ailawadi G. Bone marrow-derived $\mathrm{MCP} 1$ required for experimental aortic aneurysm formation and smooth muscle phenotypic modulation. $J$ Thorac Cardiovasc Surg 2011;142:1567-74.

41. Egashira K. Molecular mechanisms mediating inflammation in vascular disease: special reference to monocyte chemoattractant protein-1. Hypertension 2003;41:834-41.

42. Chalouhi N, Points L, Pierce GL, Ballas Z, Jabbour P, Hasan D. Localized increase of chemokines in the lumen of human cerebral aneurysms. Stroke 2013;44:2594-7.

43. Aoki T, Kataoka H, Shimamura M, Nakagami H, Wakayama K, Moriwaki T, Ishibashi R, Nozaki K, Morishita R, Hashimoto N. NF-kappaB is a key mediator of cerebral aneurysm formation. Circulation 2007;116:2830-40.

44. Aoki T, Kataoka H, Nishimura M, Ishibashi R, Morishita R, Miyamoto S. Ets-1 promotes the progression of cerebral aneurysm by inducing the expression of MCP-1 in vascular smooth muscle cells. Gene Ther 2010;17:1117-23

45. Aoki T, Kataoka H, Nishimura M, Ishibashi R, Morishita R, Miyamoto S. Regression of intracranial aneurysms by simultaneous inhibition of nuclear factor-kappaB and Ets with chimeric decoy oligodeoxynucleotide treatment. Neurosurgery 2012;70:1534-43.

46. Aoki T, Fukuda M, Nishimura M, Nozaki K, Narumiya S. Critical role of TNF-alpha-TNFR1 signaling in intracranial aneurysm formation. Acta Neuropathol Commun 2014;2:34.

47. Hoh BL, Hosaka K, Downes DP, Nowicki KW, Wilmer EN, Velat GJ, Scott EW. Stromal cell-derived factor-1 promoted angiogenesis and inflammatory cell infiltration in aneurysm walls. $J$ Neurosurg 2014;120:73-86

48. Grunewald M, Avraham I, Dor Y, Bachar-Lustig E, Itin A, Jung S, Chimenti S, Landsman L, Abramovitch R, Keshet E. VEGF-induced adult neovascularization: recruitment, retention, and role of accessory cells. Cell 2006;124:175-89.

49. Ota R, Kurihara C, Tsou TL, Young WL, Yeghiazarians Y, Chang M, Mobashery S, Sakamoto A, Hashimoto T. Roles of matrix metalloproteinases in flow-induced outward vascular remodeling. $J$ Cereb Blood Flow Metab 2009;29:1547-58.

50. Kim SC, Singh M, Huang J, Prestigiacomo CJ, Winfree CJ, Solomon RA, Connolly ES. Matrix metalloproteinase-9 in cerebral aneurysms. Neurosurgery 1997;41:642-66.

51. Takemura Y, Hirata Y, Sakata N, Nabeshima K, Takeshita M, Inoue T Histopathologic characteristics of a saccular aneurysm arising in the non-branching segment of the distal middle cerebral artery. Pathol Res Pract 2010;206:391-6.

52. Nuki Y, Tsou TL, Kurihara C, Kanematsu M, Kanematsu Y, Hashimoto T. Elastase-induced intracranial aneurysms in hypertensive mice. Hypertension 2009;54:1337-44

53. Dollery CM, Owen CA, Sukhova GK, Krettek A, Shapiro SD, Libby P. Neutrophil elastase in human atherosclerotic plaques: production by macrophages. Circulation 2003;107:2829-36.

54. Cohen JR, Keegan L, Sarfati I, Danna D, Ilardi C, Wise L. Neutrophil chemotaxis and neutrophil elastase in the aortic wall in patients with abdominal aortic aneurysms. $J$ Invest Surg 1991;4:423-30.

55. Eliason JL, Hannawa KK, Ailawadi G, Sinha I, Ford JW, Deogracias MP, Roelofs KJ, Woodrum DT, Ennis TL, Henke PK, Stanley JC, Thompson RW, Upchurch GR. Neutrophil depletion inhibits experimental abdominal aortic aneurysm formation. Circulation 2005;112:232-40.

56. Aoki T, Kataoka H, Ishibashi R, Nozaki K, Hashimoto N. Cathepsin B $\mathrm{K}$, and $\mathrm{S}$ are expressed in cerebral aneurysms and promote the progression of cerebral aneurysms. Stroke 2008;39:2603-10.

57. Loscalzo J. The macrophage and fibrinolysis. Semin Thromb Hemost 1996;22:503-6.

58. Gordon S, Taylor PR. Monocyte and macrophage heterogeneity. Nat Rev Immunol 2005;5:953-64.

59. Boorsma CE, Draijer C, Melgert BN. Macrophage heterogeneity in respiratory diseases. Mediators Inflamm 2013;2013:769214.

60. Wilson HM. Macrophages heterogeneity in atherosclerosis implications for therapy. J Cell Mol Med 2010;14:2055-65.

61. Gordon S. Macrophage heterogeneity and tissue lipids. J Clin Invest 2007:117:89-93

62. Mantovani A, Garlanda C, Locati M. Macrophage diversity and polarization in atherosclerosis: a question of balance. Arterioscler Thromb Vasc Biol 2009;29:1419-23.

63. Hasan D, Chalouhi N, Jabbour P, Hashimoto T. Macrophage imbalance (M1 vs. M2) and upregulation of mast cells in wall of ruptured human cerebral aneurysms: preliminary results. $J$ Neuroinflammation 2012;9:222.

64. Amin K. The role of mast cells in allergic inflammation. Respir Med 2012;106:9-14

65. Ishibashi R, Aoki T, Nishimura M, Hashimoto N, Miyamoto S. Contribution of mast cells to cerebral aneurysm formation. Curr Neurovasc Res 2010;7:113-24.

66. Bot I, de Jager SC, Zernecke A, Lindstedt KA, van Berkel TJ Weber C, Biessen EA. Perivascular mast cells promote atherogenesis and induce plaque destabilization in apolipoprotein E-deficient mice. Circulation 2007;115:2516-25.

67. Shi GP. Lindholt JS. Mast cells in abdominal aortic aneurysms. Curr Vasc Pharmacol 2013;11:314-26. 
68. Ollikainen E, Tulamo R, Frösen J, Lehti S, Honkanen P, Hernesniemi J, Niemelä M, Kovanen PT. Mast cells, neovascularization, and microhemorrhages are associated with saccular intracranial artery aneurysm wall remodeling. $J$ Neuropathol Exp Neurol 2014;73:855-64.

69. Hannawa KK, Eliason JL, Woodrum DT, Pearce CG, Roelofs KJ, Grigoryants V, Eagleton MJ, Henke PK, Wakefield TW, Myers DD, Stanley JC, Upchurch GR. L-selectin-mediated neutrophil recruitment in experimental rodent aneurysm formation. Circulation 2005;112:241-7.

70. Marbacher S, Marjamaa J, Bradacova K, von Gunten M, Honkanen P, Abo-Ramadan U, Hernesniemi J, Niemelä M, Frösen J. Loss of mural cells leads to wall degeneration, aneurysm growth, and eventual rupture in a rat aneurysm model. Stroke 2014;45:248-54.

71. Anidjar S, Dobrin PB, Eichorst M, Graham GP, Chejfec G. Correlation of inflammatory infiltrate with the enlargement of experimental aortic aneurysms. J Vasc Surg 1992;16:139-47.

72. Klebanoff SJ. Myeloperoxidase: friend and foe. $J$ Leukoc Biol 2005;77:598-625

73. Nicholls SJ, Hazen SL. Myeloperoxidase and cardiovascular disease. Arterioscler Thromb Vasc Biol 2005;25:1102-11.

74. Gounis MJ, Vedantham S, Weaver JP, Puri AS, Brooks CS, Wakhloo AK, Bogdanov AA. Myeloperoxidase in human intracranial aneurysms: preliminary evidence. Stroke 2014;45:1474-7.

75. Arbonés ML, Ord DC, Ley K, Ratech H, Maynard-Curry C, Otten G, Capon DJ, Teddert TF. Lymphocyte homing and leukocyte rolling and migration are impaired in L-selectin-deficient mice. Immunity 1994;1:247-60.

76. Tedder TF, Steeber DA, Pizcueta P. L-selectin-deficient mice have impaired leukocyte recruitment into inflammatory sites. J Exp Med 1995; 181:2259-64.

77. Vestweber D, Blanks JE. Mechanisms that regulate the function of the selectins and their ligands. Physiol Rev 1999;79:181-213.

78. Zhou HF, Yan H, Cannon JL, Springer LE, Green JM, Pham CT. CD43-mediated IFN- $\gamma$ production by $\mathrm{CD} 8+\mathrm{T}$ cells promotes abdominal aortic aneurysm in mice. J Immunol 2013;190:5078-85.
79. Hosaka K, Hoh BL. Inflammation and cerebral aneurysms. Transl Stroke Res 2014;5:190-8.

80. Hasan DM, Mahaney KB, Magnotta VA, Kung DK, Lawton MT, Hashimoto T, Winn HR, Saloner D, Martin A, Gahramanov S, Dósa E, Neuwelt E, Young WL. Macrophage imaging within human cerebral aneurysms wall using ferumoxytol-enhanced MRI: a pilot study. Arterioscler Thromb Vasc Biol 2012;32:1032-8.

81. Spinowitz BS, Kausz AT, Baptista J, Noble SD, Sothinathan R, Bernardo MV, Brenner L, Pereira BJ. Ferumoxytol for treating iron deficiency anemia in CKD. J Am Soc Nephrol 2008;19:1599-605.

82. Lu M, Cohen MH, Rieves D, Pazdur R. FDA report: ferumoxytol for intravenous iron therapy in adult patients with chronic kidney disease. Am J Hematol 2010;85:315-9.

83. Hasan D, Chalouhi N, Jabbour P, Dumont AS, Kung DK, Magnotta VA, Young WL, Hashimoto T, Winn HR, Heistad D. Early change in ferumoxytol-enhanced magnetic resonance imaging signal suggests unstable human cerebral aneurysm: a pilot study. Stroke 2012:43:3258-65.

84. Chen JW, Pham W, Weissleder R, Bogdanov A Jr. Human myeloperoxidase: a potential target for molecular MR imaging in atherosclerosis. Magn Reson Med 2004;52:1021-8.

85. Chen JW, Querol Sans M, Bogdanov A Jr, Weissleder R. Imaging of myeloperoxidase in mice by using novel amplifiable paramagnetic substrates. Radiology 2006;240:473-81.

86. DeLeo MJ 3rd, Gounis MJ, Hong B, Ford JC, Wakhloo AK, Bogdanov AA Jr. Carotid artery brain aneurysm model: in vivo molecular enzyme-specific MR imaging of active inflammation in a pilot study. Radiology 2009;252:696-703.

Cite this article as: Strong MJ, Amenta PS, Dumont AS, Medel R. The role of leukocytes in the formation and rupture of intracranial aneurysms. Neuroimmunol Neuroinflammation 2015;2(2):107-14

Source of Support: Nil. Conflict of Interest: No.

Received: 29-08-2014; Accepted: 06-09-2014 